\title{
RELATIONSHIP BETWEEN MINDFULNESS, SELF-COMPASSION AND DIFFICULTIES IN EMOTION REGULATION IN ADDICTS
}

\author{
Tânia Caetano, Eduardo Ramadas, \& Jessica Lopes \\ Department or Research and Development, VillaRamadas International Treatment Centre (Portugal)
}

\begin{abstract}
Difficulties in emotion regulation is one of the main characteristics of addictive disorders. Both mindfulness and self-compassion have been offered as possible alternative strategies of emotion regulation and have also been found to be connected.

Our objective was to understand how predisposition to be mindful (to be in the present moment), self-compassion and difficulties in emotion regulation relate to each other in a sample of addicts.

The present study was exploratory and has a cross-sectional design. Current results relate to 17 patients who were receiving treatment in VillaRamadas treatment center for addiction. The psychological measures used were: Mindful Attention and Awareness Scale (MAAS), Self-Compassion Scale (SCS) and Difficulties in Emotion Regulation Scale (DERS).

From the 17 participants, 13 were men. Age varied from 19 to 64 years $(M=33, S D=10.13)$. MAAS presented strong negative association with self-judgment and all its subscales, and a moderate negative association with the DERS total score. It did not show any significant association with self-compassion or any of its subscales.

The DERS total score showed strong positive associations with both the total score of self-judgment, and the subscales self-criticism and over-identification and a moderate association with isolation. It also presented a moderate negative association with self-compassion, and strong negative associations with the subscales self-kindness and mindfulness.

MAAS was a significant predictor of self-judgment, explaining $50.9 \%$ of its variability. Both self-compassion and self-judgment were significant predictors of DERS, explaining $27.4 \%$ and $55.3 \%$ of its variance, respectively.
\end{abstract}

Keywords: Mindfulness, self-judgment, self-compassion, emotion regulation, addiction.

\section{Introduction}

Mindfulness and self-compassion are constructs that frequently appear connected as important predictors of psychological health (e.g. Keng, Smoski, \& Robins, 2011; MacBeth, \& Gumley, 2012), and are growing in popularity as emerging strategies to be integrated in clinical practice. Both have been proposed as emotion regulation strategies (e.g. Tang, Hölzel, \& Posner, 2015; Berking, \& Whitley, 2014) that can be particularly useful for disorders characterized by a deficit related skills, such as addiction disorders.

Our objective with this small exploratory study was to explore the relationship between predisposition to mindfulness, self-compassion (and self-judgment) and difficulties in emotion regulation, in a clinical sample of addicts receiving treatment.

\section{Methods}

\subsection{Participants}

The sample was composed of 17 Portuguese patients, receiving treatment for an addiction disorder at VillaRamadas International Treatment Centre throughout December of 2018 and January of 2019.

From the 17 patients, 13 were male and 4 were female, and age varied between 19 and 64 years $(M=33, S D=10.13)$. All the patients had been diagnosed at admission into treatment, either with a substance use disorder or with an impulsive disorder (behavioral addiction).

\subsection{Measurements}

Mindfulness Attention and Awareness Scale (MAAS; Brown \& Ryan, 2003; Portuguese translation and adaptation by Pinto Gouveia, \& Gregório, 2013), is a 15-item self-report measure of a core 
characteristic of dispositional mindfulness, which is open awareness and attention of the present moment. The items are scored on a 6-point Likert scale from 1 ("almost always") to 6 ("almost never").

Self-Compassion Scale (SCS; Neff, 2003; Portuguese version by Castilho, Pinto-Gouveia, \& Duarte, 2015), is a set of two scales, self-compassion and self-judgment, which score is composed by the added scores of three subscales each. The subscales for the self-compassion scale are Self-Kindness, Common Humanity and Mindfulness; for the self-judgment scale are Self-Criticism, Isolation and Over-identification. All the items are scored on a 5-point Likert scale from 1 ("almost never") to 5 ("almost always").

Difficulties in Emotion Regulation Scale (DERS; Gratz, \& Roemer, 2004; Portuguese version by Veloso, Pinto-Gouveia, \& Dinis, 2011), is a self-report instrument that can calculate scores for six subscales and a total score. The 36 items that compose the scale are scored on a 5-point Likert scale from 1 ("almost never") to 5 ("almost always"). For the present study, only the total score was considered. Higher scores indicate greater emotion regulation difficulties.

\section{Results}

\subsection{Descriptive statistics}

Years of education ranged from 10 to 16 years, with a mean of 13.47 years $(S D=1.84)$.

The MAAS total score mean result was of 56.06, with $S D=11.09$.

From the SCS, the Self-Compassion total score presented a mean result of $35.12(S D=10.15)$, with a mean result of $12.76(S D=4.51)$ for Self-Kindness, of $11.47(S D=3.71)$ for Common Humanity, and of $10.88(S D=3.12)$ for Mindfulness. The Self-judgment total score presented a mean result of 39.88 $(S D=10.84)$, with a mean result of $15.88(\mathrm{SD}=4.58)$ for Self-Criticism, of $11.29(\mathrm{SD}=3.46)$ for Isolation, and of $12.71(\mathrm{SD}=3.72)$ for Over-identification.

Finally, the DERS total score had a mean result of 94.18 , with a $S D=27.11$.

\subsection{Correlation values between the studied variables (Spearman's correlation)}

Age showed a moderate positive association with both years of education and the mindfulness subscale of self-compassion.

MAAS presented strong negative association with self-judgment and all its subscales, and a moderate negative association with the DERS total score. It did not show any significant association with self-compassion or any of its subscales.

The DERS total score showed strong positive associations with both the total score of self-judgment, and the subscales self-criticism and over-identification and a moderate association with isolation. It also presented a moderate negative association with self-compassion, and strong negative associations with the subscales self-kindness and mindfulness.

The complete results are presented in Table 1.

Table 1. Correlation values between the studied variables.

\begin{tabular}{|c|c|c|c|c|c|c|c|c|c|c|c|c|}
\hline & 1 & 2 & 3 & 4 & 5 & 6 & 7 & 8 & 9 & 10 & 11 & 12 \\
\hline 1. Age & - & & & & & & & & & & & \\
\hline $\begin{array}{l}\text { 2. Years of } \\
\text { Education }\end{array}$ & $.510^{*}$ & - & & & & & & & & & & \\
\hline $\begin{array}{l}\text { 3. MAAS } \\
\text { SCS }\end{array}$ & .438 & .112 & - & & & & & & & & & \\
\hline $\begin{array}{l}\text { 4. Self- } \\
\text { Kindness }\end{array}$ & .331 & .059 & .201 & - & & & & & & & & \\
\hline $\begin{array}{l}\text { 5. Common } \\
\text { Humanity }\end{array}$ & -.116 & -.032 & .158 & $.608^{* *}$ & - & & & & & & & \\
\hline $\begin{array}{l}6 . \\
\text { Mindfulness }\end{array}$ & $.483^{*}$ & .047 & .301 & $.743^{* *}$ & $.546^{*}$ & - & & & & & & \\
\hline $\begin{array}{l}\text { 7. Self- } \\
\text { Compassion } \\
\text { Total }\end{array}$ & .315 & .102 & .203 & $.930^{* *}$ & $.750^{* *}$ & $.849^{* * *}$ & - & & & & & \\
\hline $\begin{array}{l}\text { 8. Self- } \\
\text { Criticism }\end{array}$ & -.427 & .183 & $-.651^{* *}$ & $-.671^{* *}$ & -.347 & $-.644^{* *}$ & $-.600^{*}$ & - & & & & \\
\hline 9. Isolation & -.093 & .250 & $-.668^{* * *}$ & -.342 & -.414 & -.304 & -.399 & $.610^{* *}$ & - & & & \\
\hline $\begin{array}{l}\text { 10. Over- } \\
\text { identificatio } \\
\mathrm{n}\end{array}$ & -.265 & .235 & $-.662^{* *}$ & $-.637^{* *}$ & -.353 & $-.603^{*}$ & $-.557^{*}$ & $.954^{* *}$ & $.603^{*}$ & - & & \\
\hline $\begin{array}{l}\text { 11. Self- } \\
\text { judgment } \\
\text { Total }\end{array}$ & -.326 & .162 & $-.750^{* * *}$ & $-.639^{* * *}$ & -.422 & $-.583^{*}$ & $-.598^{*}$ & $.950^{* * *}$ & $.797^{* * *}$ & $.943^{* *}$ & - & \\
\hline 12. DERS & -.385 & .038 & $-.568^{*}$ & $-.648^{* * *}$ & -.210 & $-.603^{*}$ & $-.564^{*}$ & $.850^{* * *}$ & $.491 *$ & $.803^{* *}$ & $.815^{* *}$ & - \\
\hline
\end{tabular}

Note. Values in bold indicate a statistically significant association between the respective variables. Significance level: $*=\mathrm{p}<.05$; $* *=\mathrm{p}<.01 ; * * *=\mathrm{p}<.001$. 


\subsection{Linear regression}

Three simple regression analyses were conducted, the first one with MAAS as a possible predictor of self-judgment, and the second and third with self-judgment and self-compassion as predictors of difficulties in emotion regulation, respectively.

MAAS was a significant predictor of self-judgment $(\mathrm{F}(1,15)=17.617, p=.001)$ with an adjusted $R^{2}$ of .509 . Both self-compassion $(\mathrm{F}(1,15)=7.053, p=.018)$ and self-judgment $(\mathrm{F}(1,15)=20.783$, $p<.001)$ were significant predictors of DERS, with adjusted $R^{2}$ of .274 and .553 respectively.

\section{Discussion}

Our results indicate that predisposition to be mindful is strongly associated with and a significant predictor of self-judgment in addicts, but not with self-compassion. Given the strong association between self-judgment and difficulties in emotion regulation, and taking into consideration its importance in addiction, this result could partially explain the success of mindfulness-based programs for addiction.

Given the very small sample size, the results have to be interpreted with extreme caution. Although mindfulness was not a predictor of difficulties in emotion regulation in this study, future research could explore this potential relationship and, if found, the possible mediation effect of self-judgment.

\section{References}

Berking, M., \& Whitley, B. (2014). Affection regulation training: A practitioner's manual. New York: Busines Media. doi: 10.1007/978-1-4939-1022-9_ 1.

Brown, K.W. \& Ryan, R.M. (2003). The benefits of being present: Mindfulness and its role in psychological well-being. Journal of Personality and Social Psychology, 84, 822-848. doi: 10.1037/0022-3514.84.4.822

Castilho, P., Pinto-Gouveia, J., \& Duarte, J., (2015). Evaluating the Multifactor Structure of the Long and Short Versions of the Self-Compassion Scale in a Clinical Sample. Journal of Clinical Psychology, 71(9), 856-70. doi: 10.1002/jclp.22187

Gratz K. L., \& Roemer L. (2004). Multidimensional assessment of emotion regulation and dysregulation: development, factor structure, and initial validation of the difficulties in emotion regulation scale. J. Psychopathol. Behav. Assess. 26, 41-54. doi: 10.1007/s10862-008-9102-4

Gregório, S., \& Pinto-Gouveia, J. (2013). Mindful attention and awareness: relationships with psychopathology and emotion regulation. The Spanish Journal of Psychology, 16. doi: $10.1017 /$ sjp.2013.79.

Keng, S. L., Smoski, M. J., \& Robins, C. J. (2011). Effects of mindfulness on psychological health: a review of empirical studies. Clinical Psychology Review, 31, 1041-1056. doi:10.1016/ j.cpr.2011.04.006.

MacBeth, A., \& Gumley, A. (2012). Exploring compassion: a metaanalysis of the association between self-compassion and psychopathology. Clinical Psychology Review, 32, 545-552. doi:10.1016/j.cpr.2012.06.003.

Neff, K. D. (2003). Development and validation of a scale to measure self-compassion. Self and Identity, 2, 223-250. doi: 10.1080/15298860390209035

Tang, Y., Hölzel, B. K., \& Posner, M. I. (2015). The neuroscience of mindfulness meditation. Nat. Rev. Neurosci. 16, 213-225. doi: 10.1038/nrn3916

Veloso, M., Pinto-Gouveia, J., \& Dinis, A. (2011). Estudos de validação com a versão portuguesa da Escala de Dificuldades na Regulação Emocional (EDRE). Psychologica, 54, 87-110. 